\title{
QUESTÕES SOBRE TRADUÇÃO
}

\author{
Albertina Vicentini* \\ Alice Maria Araújo Ferreira* \\ Elane Ribeiro Peixoto***
}

\begin{abstract}
RESUMO: o artigo expõe as principais vertentes teóricas dos estudos sobre tradução. Discute algumas posições sobre as questões da fidelidade, da recriação, da tradução literal e da intraducibilidade na área. Acrescenta a essas questões a ética do traduzir e a relação do ato tradutório com o Outro.
\end{abstract}

UNITERMOS: Teorias da tradução; fidelidade; recriação; intraducibilidade; ética do traduzir; outrem.

RÉSUMÉ: L'article expose les principales théories sur la traduction. Il discute certaines positions à propos de la fidélité, de la re-création, de la traduction littérale et de l'intraduisibilité dans le domaine. Il ajoute à ces questions celle de l'éthique du traduire et la relation de l'acte du traduire avec l'Autre.

MOTS-CLÉ: Théories de la traduction; fidélité; re-création; intraduisibilité; éthique du traduire; autrui.

* Doutora em Teoria Literária e Literatura Comparada pela USP. Professora do Mestrado em Letras /UCG.

** Doutora em Lingüística pela USP. Professora do Mestrado em Letras / UCG.

*** Doutora em Arquitetura e Urbanismo pela USP. Tradutora e professora do Mestrado em Territorialidade da UCG. 
Os estudos da tradução são recentes, mas já desenvolvem uma importante discussão. Segundo Ofir Bergemann de Aguiar (2000), podem-se alinhavar cinco vertentes teóricas nessa área de estudos.

a) As oficinas de tradução norte-americanas - que concedem à atividade estatuto autônomo nos currículos universitários, e possuem como escopo propor regras e princípios que possam decodificar, através de soluções "corretas e únicas", a significação original de um texto a ser recodificado, em seguida, em uma outra língua. "A preocupação com a associação de palavras, etimologias e ressonâncias tem estado presente em suas atividades" (idem, ibidem, p. 19), tanto quanto a possibilidade de uma máquina de tradução.

b) A 'ciência' da tradução - cujo grande representante é Eugene Nida (1964) que, a partir da teoria dos universais lingüísticos de Noam Chomsky, escreveu Toward a Science of Translating, tido como o manual da teoria da tradução, sobretudo nos Estados Unidos e na Inglaterra. Segundo ele, dentro dos "componentes básicos da lingüística gerativa, a preocupação primeira da tradução deve concentrar-se "na comunicação, entre culturas, do espírito de uma mensagem original, devendo ser negligenciada a forma com que essa mensagem é transmitida" (Aguiar, 1999:21). Elaborou também o conceito de equivalência dinâmica, em que "a mensagem do original é transposta de modo a produzir, junto ao público receptor da tradução, o mesmo efeito obtido com o original" (idem, ibidem, p. 22)

c) Estudos de tradução - provenientes da Holanda, obtiveram a liderança de James Holmes. Negam que uma obra em si detenha qualquer 'verdade transcendental' ou se apresente como um "texto fixo que possa ser cientificamente determinado". Postulam que, na tradução, "não ocorre somente transferência entre culturas, con- 
forme afirma Nida, mas também uma mediação entre mediações históricas. [Ademais,] a tradução, segundo Holmes, não se refere ao mesmo objeto do mundo real que o texto-fonte, mas a uma formulação lingüística: trata-se de signos que remetem a outros signos" (Aguiar, 1999:27). A tradução, portanto, deixa, com essa vertente, "de ser componente de uma dicotomia estática texto de partida e texto de chegada - passando a ser vista como um passo em uma cadeia de interpretação, pois é a interpretação de um signo, sendo ela mesma sujeita a interpretações" (idem, ibidem). As relações entre o texto original e o traduzido incluem as tradições das culturas que se permutam. Com isso, podem ser identificados quatro tipos de tradução: as que retêm a forma do original; as que compartilham a mesma função; as que desenvolvem formulação própria; e as que apresentam pouca similaridade com o original (idem: 28). Além disso, nos estudos da tradução são três as grandes áreas: a descritiva (que detalha como as traduções se efetivam); a teórica (como as traduções podem ser explicadas); e a aplicada (que utiliza os resultados das traduções anteriores no ensino, na crítica e na elaboração de gramáticas contrastivas e máquinas de traduzir).

d) Estudos descritivos da tradução - derivados das pesquisas da Universidade de Tel-Aviv, Israel, ampliam os sistemas das culturas envolvidas na tradução para polissistemas, internos também a cada uma dessas culturas - sistemas literário, de gênero, extraliterário, etc -, em relação hierárquica entre si e dentro de uma norma (a familiar). Introduz-se, nos estudos, a perspectiva histórica, que se desenvolve, inclusive, na avaliação de componentes ideológicos e coerções culturais.

e) A desconstrução - que abalou o caráter de presença sagrada conferida ao texto original. Aqui, um texto só é original (fonte) se traduzido. Entende-se a tradução como 
desconstrução logocêntrica; ou seja, corroboração de que, de fato, "não existem significados estáveis e independentes do jogo lingüístico, que é baseado no princípio da diferença e da arbitrariedade" (Aguiar, 1999:43). Contra, portanto, os universais da estrutura profunda das línguas, essa vertente defende o ponto de vista subjetivo (função de autor) e histórico daquele que traduz. Não desvincula forma, conteúdo e linguagem. Ao contrário, esta é auto-referente, sendo a tradução uma prova disso, porque tradução (em linguagem) é tradução de uma tradução anterior (em linguagem) do mundo.

Essas cinco vertentes, de certa forma, discutem duas outras questões tradicionais na área de tradução: a da fidelidade / impossibilidade ou não da tradução, e a questão da tradução literal, essa última especialmente.

A primeira encontra hoje, na área dos estudos lingüísticos, e principalmente em relação a textos literários, pelo menos três discussões que não se excluem:

a) a intraducibilidade de qualquer texto;

b) a tradução como forma de recriação;

c) a discussão de que toda significação sígnica é uma forma de leitura mesmo dentro da própria língua, e a tradução nada mais é que uma leitura efetuada de uma cultura lingüística para outra.

$\mathrm{O}$ argumento em favor da primeira discussão considera a linguagem poética (e mesmo a filosófica) como uma entidade única, cujos conteúdos são tão absolutamente presos à estrutura formal de base que qualquer modificação de seus elementos gera uma "outra representação" que não a sua, imperfeita e infiel ${ }^{1}$. A estrutura é, portanto, original, e a tradução (traducere

1 Essa tem sido a principal categoria com que os estudos literários se desenvolveram no século XX, desde o Formalismo Russo. Conferir para tal, os seus principais teóricos: Roman Jakobson, Wellek e Warren, Pound, Fabri, Max Bense, Lotman, para citar alguns. 
que, em latim, significa levar alguém para outro lugar) é uma separação do encontro único entre significante e significado; encontro que faz a língua poética perder sua integridade estética, até porque, nas diferenças que se encontram de uma língua para outra - locuções, adjetivos, correspondências nominais, verbos etc -, esse desencontro está a priori colocado. Ademais, uma tradução mais próxima do perfeito, sob esse ângulo, implicaria a retomada das 'intenções' do autor ${ }^{2}$ (empresa impossivel), a coincidência da cultura das duas línguas - a traduzida e a tradutora -, o que representa outra impossibilidade e, equivocadamente, a separação forma/conteúdo ou sentido e palavra. Em outros termos, traduzir é, para puxar o consabido trocadilho, trair o texto original.

Com respeito à segunda discussão, a tradução recriadora, não se desconfiam das assertivas da intraducibilidade perfeita. Ao contrário: dela parte-se para assegurar a tradução como uma arte. Segundo Paulo Ronái (1956), o tradutor é o que se empenha em "traduzir o intraduzivel", ou seja, a transposição pode ser impossivel, mas "o objetivo de toda arte não é algo impossível?” Dessa forma, a tradução passa a ser uma outra criação, fundamentalmente reciproca e paralela. Em Haroldo de Campos (1967), maior defensor dessa postura, o procedimento de recriação tradutora é elucidado. Diz ele:

Teremos (...) uma outra lingua, uma outra informação estética, autônoma, mas ambas estarão ligadas entre si por uma relação de isomorfia: serão diferentes enquanto linguagem, mas, como os corpos isomorfos, cristalizar-se-ão dentro de um mesmo sistema (...) Numa tradução dessa natureza, não se traduz apenas o significado, traduz-se o próprio signo, ou seja, sua fisicalidade, sua materialidade mesma (propriedades sonoras, de imagética visual, enfim tudo aquilo que forma, segundo Charles Morris, a $\underline{\text { iconicidade do signo estético, entendido por signo icônico }}$

2 Para a discussão dessa questão, veja-se dois textos clássicos sobre o assunto: "A falácia intencional", de W.K.Wimsatt e M.C.Beardesley e "Pierre Menard, autor do Quixote", de Jorge Luís Borges. 
aquele "que é de certa maneira similar àquilo que ele denota ). O significado, o parâmetro semântico, será apenas e tão somente a baliza demarcatória do lugar da empresa recriadora. Está-se pois no avesso da chamada tradução literal. (Campos, 1967:24, grifos do autor)

Importa, portanto, para a tradução, ser antes fiel ao clima, ao tom ou à 'gestalt' final da obra, acrescentando-lhe, quando necessário, "numa contínua sedimentação de estratos criativos, efeitos novos ou variantes, que o original autoriza em sua linha de invenção" (idem, ibidem, 26)

Essa linha de invenção ${ }^{3}$ faz concluir que o trabalho que precede a tradução é, por conseqüência, crítico e técnico. Ou seja, análise e comparação do material que se tem em mãos a traduzir, refazendo "as etapas criativas da elaboração do texto, repetindo as operações de testagem e eleição de cada linha do poema entre as várias que se apresentavam (apresentam) à mente (do poeta), tendo em vista sempre o projeto e as exigências do texto" (idem, ibidem, 32).

Em que pesem as diferenças, dado que a tradução literal é a que mais se perde nas teias do texto, essa segunda linha de argumento pressupõe, como a da intraducibilidade, a questão das intenções literárias a serem re-descobertas no texto pelo tradutor que, de uma forma ou de outra, acaba por manter uma capacidade criadora igual ou superior à do autor (ou do texto). No entanto, acaba também, o tradutor, e positivamente, por mostrar uma capacidade pedagógica, no sentido de que exibe os 'materiais' de fatura do poema, os seus padrões estruturais criativos, constituindo sua leitura numa forma privilegiada de crítica porque metalingüística. $\mathrm{E}$ contribui, por tangente, para o estudo da teoria da literatura, na própria medida em que é da crítica que se formula a teoria. Ademais, transforma o tradutor (sempre marginalizado e mal visto) num artista e num crítico ao mesmo tempo, tanto quanto num especialista, cedendo-lhe

3 A invenção também é defendida por T.S. Eliot, no sentido do 'olho criativo', acrescentado da capacidade de ver o passado com as suas diferenças, mas recriando-o como presente, no sentido de uma presentificação. Cf. Eliot (1944).

TradTerm, 14, 2008, p. 177-192 
um lugar altivo e fundamental para os estudos literários e lingüísticos.

A questão da leitura, porém, já é corolário da terceira vertente de que vimos tratando. Essa vertente começa por desfazer a questão da autoria como 'presença' ou 'origem' (originalidade também) do texto, demonstrando-a como logocêntrica ou pertencente à metafísica da presença, na crítica de Jacques Derrida. Desconstrutora, o lugar que ela cede ao texto é o do intertexto, numa mesma língua ou em qualquer outra, e o do arbitrário, ou da falta de relação direta e motivada entre o significante e o significado, conforme expôs F. de Saussure. A língua é uma convenção social, e o signo não possui essência, mas diferença em relação aos outros elementos do sistema que integra, o que pressupõe que nenhum deles se refira a si próprio - pode haver modificação no valor de um desses elementos pela simples justaposição de um outro, sem tocar-lhes no sentido ou no som. Nessa ótica, não há formação original e pré-lingüística, sendo somente o jogo interdependente de diferenças que forma o sentido. E nesse jogo, a cada vez apagam-se diferenças, como explica Nietzsche:

Quando falamos de árvores, cores, neves e flores, acreditamos saber algo a respeito das coisas em si, mas somente possuímos metáforas dessas coisas, e essas metáforas não correspondem de maneira alguma à essência do original. (Nietzsche apud Arrojo, 1992:422)

O que ocorre, segundo Nietzsche, é que se trata o diferente como idêntico, apagando-se o desigual:

Certamente nenhuma folha é exatamente igual a qualquer outra. Assim, a idéia 'folha' se formou através da omissão arbitrária dessas diferenças individuais, através de um esquecimento das qualidades diferenciais, e tal idéia sugere a noção de que na natureza existe, além das folhas, algo chamado 'a folha', talvez uma forma original de acordo com a qual todas as folhas foram tecidas, desenhadas, precisamente medidas, coloridas, enrugadas, pintadas, mas por mãos inábeis, de tal modo que nenhuma cópia 
tenha saído correta e fiel à forma original. (idem, ibidem: 422)

As manifestações lingüísticas, portanto, não importa se enunciadas dentro de uma mesma língua ou de uma língua para outra, são sempre traduções claudicantes, imperfeitas, que usam como instrumento os signos estabelecidos em acordo social, adiando indefinidamente uma significação única e original. O que existe é interpretação, produção de sentido no jogo do sistema de diferenças que é a língua. Toda manifestação é, portanto, em si, uma leitura, e a tradução, uma leitura como as outras.

A concepção freudiana do inconsciente também participa dessa discussão, na medida em que desconstrói a "ilusão de presença do 'cogito' cartesiano”. Diz R. Arrojo:

O sujeito dotado de um inconsciente é, em primeiro lugar, constituído por diferenças. Dividido entre a consciência, a libido do id e as pressões do superego, esse sujeito tem de renunciar à ilusão de uma supremacia racional e conviver com o desconhecimento que determina suas escolhas e esboça o seu destino. O inconsciente representa, como observa Paul-Laurent Assoun: o regime crônico do agir humano, a cisão incessantemente reativada entre o querer e o agir, o verdadeiro e o falso, o dito e o calado. Designa sempre a ilusão, mas apreendida doravante na imanência do comportamento moral. Que o homem faça incessantemente uma coisa diferente do que crê fazer, eis o que institui o desconhecimento no cerne da realidade humana e universaliza o inconsciente como linguagem deste desconhecimento crônico. (Arrojo, 1992:425)

De novo, a manifestação lingüística é também desprovida de uma intencionalidade que possa ser cabal, no sentido de que desconhece alguma perspectiva que assinalou. E, na medida em que o inconsciente participa do sujeito, ele também lê inclusive seu próprio discurso no objeto que diz. O autor é, também, nessa perspectiva, um leitor, assim como o é o tradutor.

O que de fato essa vertente deixa para trás é o fim da ilusão humana de um mundo de essências que se pode atingir 
(principalmente pela arte literária ou pela filosofia). A crença de que determinados conceitos, categorias ou estruturas não dependem da linguagem é derrotada. A linguagem é uma forma de tradução, de leitura, e é um jogo de diferenças. Assim, perigosamente, o mundo se transforma somente em linguagem.

A tradução, então, não é o transporte imperfeito de estruturas, mas uma outra leitura, "a transformação de um texto em outro, de uma cultura em outra, desde que aceitemos a diferença e a impossibilidade do retorno ao mesmo, ao mesmo livro, ao mesmo poema" (Arrojo, 1992:436).

Entretanto, essas três vertentes mantêm um ponto em comum: a consciência da intradutibilidade perfeita, porque forma e conteúdo são alienados. Mas tal pode se dar não porque o texto a ser traduzido seja original, ou a língua poética seja uma língua à parte dentre as manifestações lingüísticas, mas porque a tradução é uma forma de leitura, afinal, na manifestação da linguagem, todo enunciador é um leitor/tradutor, porque o signo lingüístico é arbitrário e só significa no jogo das diferenças. Dessa maneira, a intraducibilidade de fato inexiste, e a sua perfeição deixa de ser escopo fundamental. Toda tradução é uma outra estrutura, uma re-tradução.

Nesse sentido, cresce a importância da tradução como atividade: primeiro, porque passa a ser a atividade paradigmática do que é a própria construção dentro da linguagem - uma tradução com diferenças; segundo, porque intercambia estruturas lingüísticas, ou seja, 'dissemina', reproduz os sentidos - uma forma de escritura produtiva que "se assume como uma inevitável forma de conquista ou tomada de poder, que necessariamente reescreve o passado e se apropria de outras culturas e linguagens. Como ensina Nietszche, o grau do sentido histórico de qualquer época pode ser avaliado a partir da forma pela qual essa época traduz e tenta absorver épocas e livros anteriores". (Arrojo, 1992:437)

Também, é a tradução (assim como a leitura) que põe em circulação o texto, que vive, principalmente, porque é lido ou traduzido: "se o poético pudesse estar realmente no poema e ser evidente em si mesmo, dispensando qualquer relação com o leitor (ou tradutor), não estaria também morto e encerrado? Ou, 
congelado numa leitura única e definitiva, enterrado nos signos intocáveis do poema, de que nos serviria o estético ou o poético?" (idem, ibidem:437)

Isso suposto, a tradução é, portanto, como diz Haroldo de Campos (Campos, 1967:25), uma pedagogia, pois, "enquanto diversifica as possibilidades de [um] idioma poético, põe à disposição dos novos poetas, amadores de poesia (e críticos) todo um repertório (muitas vezes insuspeitado ou obscurecido pela rotinização do gosto acadêmico e do ensino da literatura) de produtos poéticos básicos, reconsiderados e vivificados".

Quanto à tradução literal, essa tem sido considerada inadequada e quiçá impossivel, com base nas análises "científicas das línguas, pela qual se comprova, a despeito dos graus variáveis de proximidade e distância tipológica e cultural, a inexistência de estruturas (léxico-semânticas, sintáticas, grafo-fonológicas) idênticas entre elas" (Aubert, 1987:12).

Os possiveis "universais lingüisticos, se comprovados, devem situar-se em niveis mais profundos e abstratos". Além disso, dado que cada língua manifesta uma cosmovisão, qualquer tradução é mudança de perspectiva, em "que se diz o mundo diferentemente" (idem, ibidem:14). Ficar no nível profundo do enunciado para chegar nesses possiveis "universais lingüísticos" é esquecer, como diz Henri Meschonnic, que o pensamento faz algo à linguagem, e que é o que ele faz que temos que traduzir. Nos termos de Meschonnic, "Il n'y a qu'une source, c'est ce que fait un texte ; il n'y a qu'une cible, faire dans l'autre langue ce qu'il fait"4. (Meschonnic, 1999:23).

Os autores que aceitam essa tradução, como Jakobson (1977:64-5): a tradução é "a interpretação dos signos verbais por meio de uma outra língua"), colocam-na como equivalência - "sinonímia interlingual transitória" - mais de sentido do que de forma. Quando é necessário, os tradutores utilizam-se de organizações textuais mais ou menos diferentes do texto de partida, por questões antropoculturais e gramático-lexicais, etc. Jakobson pode, com suas ferramentas analiticas, chegar à ana-

4 "Só existe uma fonte, o que faz o texto; só existe um alvo, fazer na outra língua o que ele faz."

TradTerm, 14, 2008, p. 177-192 
tomia do texto, mas apenas atinge o morto, o descritivo, esquemas de funcionamento da língua. Parece não conseguir chegar à vida: no que faz o texto à língua, o que se deve justamente traduzir.

O conceito de tradução literal, no entanto, se explicita de várias formas:

a) pode ser entendido como tradução ao pé-da-letra, isto é, a expressão na língua de chegada mantém o mesmo (aproximadamente) semantismo e a ordem sintática dos vocábulos da língua de partida - tradução literal propriamente dita;

b) pode ser entendida como a que mantém fidelidade semântica estrita, mas adequando a morfossintaxe "às normas gramaticais da língua de chegada - transposição;

c) a tradução literal fideliza a semântica/contexto, adequando a morfossintaxe e o estilo "às normas e usos da língua de chegada” - modulação.

Evidente que (a) é menos usual do que (b) e (c), embora o tipo de texto e de tradução empreendida devam estar presentes: uma tradução de registro de terras, por exemplo, há de se aproximar mais de (a), com menos criatividade e mais literalidade.

Além disso, os sistemas lingüísticos acham-se abertos a manifestações da literalidade, especialmente na estrutura lexical das terminologias técnicas e científicas, "em que predomina o denotativo sobre o conotativo, o universal sobre o culturalmente marcado na relação constante entre significante e significado, embora não sejam infensos aos condicionamentos histórico-culturais" (idem, p. 19).

Assim, a literalidade não é totalmente inviável, nem se confunde com a inadequação. Ao contrário: para textos teóricos, técnicos e científicos, é viável, inclusive porque evita o subjetivo e o criativo, desde que apreenda a historicidade do texto traduzido e procure exercitar uma metodologia a qual compreenda: 
a) a mediação ideológica, ou o dominante comum, do texto através de notas;

b) diferenças lingüísticas e diferenças de normas, cultura, sociedade, gramática etc.;

c) as 'Vertaaltranformaties', ou transformações que ocorrem durante a tradução: mudanças de palavras, de sentido ou função, solucionadas por via do raciocínio lógico, acréscimos, omissões;

d) questões de estilística, um dos maiores problemas da tradução;

e) mecanismos de compensação, que recuperam numa frase o que parece perdido em outra;

f) questões gramaticais, mais especificamente de categorias gramaticais: tipos de frases, sua complexidade, orações subordinadas, estrutura da frase, grupos de palavras, classes de palavras.

Dessa forma, traduzir é possivel e faz bem.

Mas existem outras questões envolvidas no traduzir. Questões que dizem respeito à ética e à política do traduzir. Elas foram levantadas por Henri Meschonnic, em Poétique du traduire (1999), e por Antoine Berman, em L'épreuve de l'étranger (1984).

O que interessa é o traduzir e não a tradução; o ato e não o produto, pois, como nos lembra Meschonnic: "comme le langage, la littérature, la poésie sont des activités avant de laisser des produits"5. (Meschonnic, 1999:12). Traduzir é uma prática marcada por um sujeito, por uma época. A tradução tem a historicidade do discurso e sua subjetividade. Entretanto, ela dialoga com um outro e é com essa interdiscursividade que nos deparamos quando lemos uma tradução.

\footnotetext{
5 "Como a linguagem, a literatura e a poesia, são antes atividades que produtos”.
} 
É a partir da relação dialógica entre duas línguas, duas culturas, enfim entre diferenças, que podemos situar e discutir a questão da ética no traduzir. Pois traduzir é traduzir o diferente. $\mathrm{O}$ ato ético consiste em reconhecer e receber o outro enquanto outro. Uma ética do traduzir procura estabelecer uma relação dialógica entre as línguas num eixo horizontal. O reconhecimento da alteridade constitui o fundamento de toda mudança, de qualquer intercâmbio social livre. O que está em jogo na história da tradução é a própria história das relações socioeconômicas e políticas entre os povos. Meschonnic lembra que, das grandes civilizações, a ocidental é a única cujos livros fundadores são traduções: do grego, para a ciência e a filosofia, e do hebraico para a Bíblia. A história da Europa se confunde com a história da tradução. Por isso, segundo o autor, uma série de apagamentos aparece na história. Uma tradução que apaga seu fazer é justamente aquela que, no transporte de um texto de uma língua para outra, esquece completamente o ponto de partida para melhor significar sua inserção definitiva, em vez de se colocar na linha movediça do descentramento em que Eu e Outrem são os dois pólos da subjetividade.

O traduzir costuma ser o ponto fraco das teorias da linguagem, porque é o lugar em que a confusão entre língua e discurso é mais freqüente. A língua é o sistema da linguagem que identifica uma cultura, uma literatura, um povo. Assim, traduzir parece ser a passagem do que diz uma língua para outra. Mas o discurso é a atividade de um homem que fala e, como diz Humboldt: "historiquement nous avons jamais affaire qu'à l'homme réellement en train de parler"6. (Humbolt apud Meschonnic, 1999:12). A tradução tem, nesse sentido, relações estreitas com a experiência da antropologia e, por isso mesmo, com as questões de identidade e de alteridade.

A tradução, enquanto ato de linguagem, não pode ser confundida com o original, já que ela tem sua própria historicidade: a do sujeito e a da época do traduzir. O desejo de apagamento do ato do traduzir manifesta a permanência do mito de Babel e a nostalgia de uma língua única: "le mal à effacer est toujours la

6 "Historicamente, só lidamos com o homem realmente falando". 
différence et la diversité des langues"7 (Meschonnic, 1999:19). Ora, traduzir é traduzir o diferente, o Outro enquanto Outro.

A intensificação das relações internacionais não se limita às necessidades comerciais e politicas, mas também passa pelo reconhecimento de que a identidade não é mais a universalização e só acontece na alteridade, por uma pluralização na lógica das relações interculturais.

Antoine Berman, em L'épreuve de l'étranger, de 1984, inaugura tal pensamento privilegiando as relações interculturais com o outro nas teorias da tradução. Ele articula "une visée éthique du traduire" ${ }^{8}$ em termos de reconhecimento do Outro: "L'essence de la traduction est d'être ouverture, dialogue, métissage, décentrement. Elle est mise en rapport, ou elle n'est rien" ${ }^{\text {. }}$ (Berman, 1984:16). A tradução se apresenta, então, não mais como ato de assimilação, mas como um reconhecimento da diferença interlingüistica e intercultural. Esse descentramento só é possível a partir de uma concepção dialógica do traduzir, em que o sentido e o efeito de sentido não se situam mais no sujeito/enunciador, mas na relação interlocutiva existente entre o original e a tradução. Assim, na concepção de Berman, a ética se torna uma "epistemologia que articula um pensamento dialógico para pensar o idêntico em relação ao outro, de maneira a suscitar uma educação para a estranheza e acolher o estrangeiro sem negá-lo e sem apropriá-lo" (Berman, 1984:86).

Todavia, essa lógica das relações, em que o idêntico é oriundo da mediação do outro, esbarra nas resistências profundas das estruturas etnocêntricas de qualquer cultura que busca conservar sua auto-suficiência num retorno a ela mesma. A tradução ocupa, então, um lugar ambíguo; ou seja, ao mesmo tempo abertura e apropriação violenta numa dialética de reversibilidade entre fidelidade e traição. Desse modo, a partir de uma crítica da tradução que busca estabelecer uma relação dialógica entre língua materna e língua estrangeira no eixo da história da tra-

\footnotetext{
"O mal a ser apagado é sempre a diferença e a diversidade das linguas". "uma intenção ética do traduzir".

"A essência da tradução é de ser abertura, diálogo, mestiçagem, descentramento. Ela é relação ou não é nada”.
} 
dução, Berman procura colocar a necessidade de uma ética no traduzir. Para tanto, a tradução deve ser vista como criação e não apenas como transmissão, e funcionar como um modelo do saber na busca de uma verdade, muito mais que buscar fundar a autoridade de uma comunidade discursiva intercultural. Nesse sentido, se aproxima de um modelo hegeliano, em que o reconhecimento do outro se faz no terreno da ética, e não de um modelo kantiano, com a moralidade de uma consciência do sujeito.

A partir de tal reflexão sobre a ética do traduzir, a tradução pode se tornar o modelo do processo interlingüístico, intercultural, interliterário e interdisciplinar. As questões sobre a tradução não se limitam à lingüística e à poética, mas são bem mais amplas, contemplando uma multiplicidade de domínios, sobretudo o intercultural. Fala-se, assim, de uma virada cultural em tradução, generalizando o paradigma culturalista proveniente da etnologia, que trabalha a questão da estranheza em tradução. Enfim, nessa perspectiva, toda reflexão sobre uma ética do traduzir situa-se na relação entre fatos e valores, entre o que é dado e o que é criado numa relação diferencial. Pois a ética do traduzir deve partir sempre da heterogeneidade criada pelas determinações históricas e sociais. A tradução não é mais uma simples manipulação de palavras, nem de proposições, mas a relação de culturas complexas que produzem uma transvaloração cultural, cujo reconhecimento do outro sustenta as relações de poder.

\section{Referências bibliográficas}

AGUIAR. Ofir B. (2000) Abordagens teóricas da tradução. Goiânia: UFG. ARROJO, Rosemary (1992) Tradução. In: JOBIM, J.L. Palauras da crítica. RJ: Imago.

AUBERT, Francis (1987) A Tradução literal: impossibilidade, inadequação ou meta? In: Tha do Desterro: $17,1^{\circ}$ sem. (Tradução) BERMAN, Antoine (1984) L'épreuve de l'étranger. Paris: Gallimard. CAMPOS, Haroldo (1967) Da tradução como criação e como crítica. In: BERMAN (1967) Metalinguagem. Petrópolis: Vozes. 
CRYSTAL, David (1987) The Cambridge Encyclopedia of Langage. Cambridge University Press.

ELIOT, T.S. (1944) Eurípedes y el Profesor Murray. In: CRISTAL, D. (1944) Los poetas metafisicos y otros ensayos sobre teatro y religión. Buenos Aires: Emecé Editores (Tomo I). MESCHONNIC, Henri (1999) Poétique du Traduire. Paris, Verdier. RÓNAI, Paulo (1956) Escola de tradutores. RJ: Livraria São José. 